\title{
Silica coating for interphase bond enhancement of carbon and AR-glass Textile Reinforced Mortar (TRM)
}

\author{
C. Signorini ${ }^{\mathrm{a}}$, A. Nobilic ${ }^{\mathrm{c}, *}$, E.I. Cedillo Gonzalez ${ }^{\mathrm{b}}$, C. Siligardi ${ }^{\mathrm{c}}$ \\ ${ }^{a}$ Dipartimento di Scienze e Metodi dell'Ingegneria, via Amendola 2, 42122 Reggio Emilia, \\ Italy \\ ${ }^{b}$ Facultad de Ciencias Químicas, Universidad Autónoma de Nuevo León, Guerrero y \\ Progreso s/n Col. Treviño, Monterrey 64570, México \\ ${ }^{c}$ Dipartimento di Ingegneria Enzo Ferrari, via Vivarelli 10, 41125 Modena, Italy
}

\begin{abstract}
In this paper, we investigate the effect of silica nano-coating for interphase bond enhancement on the mechanical performance of Textile Reinforced Mortar (TRM) composite materials aimed at structural rehabilitation and strengthening. Alkali-resistant glass (ARG) and carbon fabric reinforcements are preliminarily treated via sol-gel deposition of $\mathrm{SiO}_{2}$ coating to promote bond formation capability with the mortar matrix. Optical and electron microscopy provide evidence of interphase bond enhancement. Mechanical performance is assessed both in traction, through uni-axial elongation of prismatic coupons, and in flexure, by three-point bending of laminated masonry bricks. Results are given in terms of mean strength curves, ultimate and design strength and strain values, cracked and uncracked moduli, mean crack spacing, mean crack width and energy dissipation. It is shown that mean absolute performance of silica coating offers a significant improvement over uncoated fabric, yet it is inferior to that of specimens which have been treated with a liquid partially-organic adhesion promoter (polymer coating). However, when design values are considered which incorporate the dispersion of experimental data, silica coating proves superior or at least equivalent to polymer coating, respectively for carbon and ARG fabric. These promising results describe the first application of silica nano-coating to fabric reinforced composite materials.
\end{abstract}

Keywords: Inorganic nano-coatings, Fabric reinforced Cementitious Material, Interphase bond

\section{Introduction}

Textile Reinforced Mortar or Concrete (TRM and TRC, respectively) constitute a novel class of composite materials recently developed for structural

${ }^{*}$ Corresponding author

Preprint submitted to Elsevier

December 22, 2017 
rehabilitation and strengthening $[1,2]$. Besides several attractive features, such as substrate compatibility, intervention reversibility, water vapour permeability and enhanced fire and aggressive environment resistance, TRM and TRC present some substantial disadvantages, especially when compared with the well-established technology of Fabric Reinforced Polymers (FRP) or even when compared to ferrocement. Indeed, their performance is mainly driven by interphase compatibility, that is the surface adhesion between the matrix and the fabric reinforcement, and common fabric reinforcement materials present inadequate interphase compatibility with cement-based binders $[3,4]$. As a result, delamination is the predominant failure mode and it is most often associated with large data scattering and a not entirely consistent performance $[5,6]$. Among TRM and TRC materials, Fabric Reinforced Cementitious Matrix (FRCM) composites attempt to bridge the performance gap with FRPs through modification of the inorganic binder with an organic component. In fact, the recently published guidelines [7] advocates, for FRCM materials, the adoption of a "polymer-modified cement-based binder (mortar)" as the composite inorganic matrix.

Alternative to matrix modification, thermal and particularly chemical treatment of the reinforcement have been investigated in order to improve adhesion with the cementitious matrix [8]. One possible approach consists of developing a hydrophilic condition on the fiber surface $[9,10,11]$, which increases wettability by the cementitious matrix and it leads to diffuse bond formation. As an example, cold gas plasma has been used to remove the hydrogen atoms from the polymer backbone of polyethylene fibers and to replace them by polar groups [12]. This approach may be extended and the specific polar group is connected to the adopted gas. The presence of polar functional chemical groups on the fiber surface increases reactivity and thus improves the reinforcement-to-matrix adhesion. In the case of carbon fibers, [9] improved the surface bond strength with Portland cement by chemical oxidation of the reinforcement surface with ozone. This treatment leads to the formation on carbon fibers of oxygen-containing functional groups, which improve water wettability and, consequently, fiber/matrix bond. Surface bond enhancement with Portland cement is achieved in [11] by performing silane and potassium dichromate treatment of carbon fibers. Results suggest that the hydrophilic nature of silane improves bond formation with cement. Moreover, similarly to ozone, dichromate treatment entails surface oxidation, which results in the appearance of oxygen-containing functional groups that enhance hidrophilicity, and consequently, adhesion.

Coating and sizing have been recently proposed as a mean to provide improved strength, consistency as well as extended durability, respectively through interphase bond enhancement, defect healing and fabric protection. In [13], a polymeric surface coating is considered to protect glass fabric from deterioration in a highly alkaline environment, such is that associated with cementitious matrices. Indeed, in [14] it is demonstrated that the quality of glass-to-cement bond changes in time, even for ARG fabric, owing to chemical and mechanical damage. Similar results are shown in $[15,16,17,18]$ in the framework of 


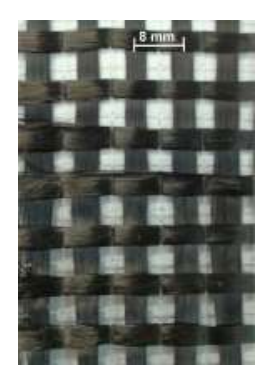

(a)

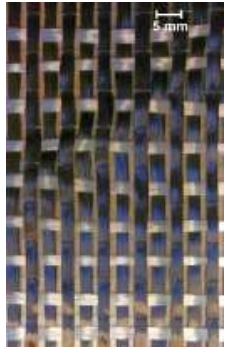

(b)

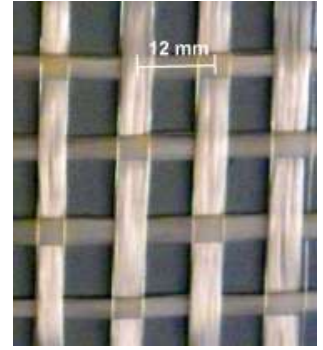

(c)

Figure 1: Reinforcement fabrics: (a) bi-axial carbon square-grid, coded C1, (b) uni-axial carbon square-grid, coded C2, and (c) bi-axial AR-Glass square grid, coded ARG

a wide spectrum durability analysis. Recently, nano-structured coatings have been used to fill-in natural surface flaws in ARG fabric and thus fully deploy their expected mechanical performance $[19,20]$. The same treatment is shown to possess a positive bearing on durability. The same approach is extended in [21] to carbon fabric, where a polymer (epoxy resin) coating is considered, also in conjunction with Multi-Walled Carbon Nanotubes (MWCNT) and/or organoclays.

In the recent contribution [22], sol-gel application of a silica nano-layer is investigated to enhance the pull-out strength of polypropylene fibers adopted in Fibre Reinforced Concrete (FRC) [23]. Similarly, although in the context of pollution reduction, [24] considers a $\mathrm{SiO}_{2}$ interlayer deposited on a stainless steel substrate via a sol-gel technique, to secure adhesion of a $\mathrm{TiO}_{2}$ photocatalyst layer. In this paper, the same hydrophilic $\mathrm{SiO}_{2}$ nano-layer is proposed as a simple and relatively low-cost procedure to obtain interphase modification of ARG and carbon fabric reinforcement in a cementitious mortar. Although applications of silica coatings form a vast body of literature, to the best of the authors' knowledge this is the first contribution investigating the effect of silica sol-gel deposition on the mechanical performance of continuous reinforcements for structural purposes.

\section{Materials and method}

\subsection{Materials}

In this study, to better emphasize the role of the coating, a single pozzolanbased mortar, already adopted in [6], is employed as the cementitious binder for the composites. This semi-hydraulic low-modulus mortar, whose mechanical properties are gathered in Tab.1, has proven particularly suitable in combination with the partially-organic adhesion promoter (supplied by Ardea Progetti e Sistemi Srl). Besides, it corresponds to mortar B of [16] and its effect on performance degradation of ARG fabric is already well documented.

Both AR-Glass and carbon fabric reinforcements are considered and their main mechanical properties are gathered in Tab.2. Carbon reinforcement is a 


\begin{tabular}{|l|c|c|}
\hline Characteristic & Unit & Value \\
\hline Mean compression strength after 28 days & $\mathrm{MPa}$ & 6.5 \\
Mean flexural strength after 28 days & $\mathrm{MPa}$ & 3 \\
Support adhesion strength after 28 days & $\mathrm{MPa}$ & 1 \\
Water content & - & $23 \%$ \\
Aggregate maximum size & $\mathrm{mm}$ & 0.7 \\
Longitudinal elastic modulus & $\mathrm{GPa}$ & 11 \\
\hline
\end{tabular}

Table 1: Mortar properties

\begin{tabular}{|l|c|c|c|c|}
\hline Characteristic & Unit & $\mathrm{C} 1$ & $\mathrm{C} 2$ & $\mathrm{ARG}$ \\
\hline Yarn count & $\mathrm{tex}$ & 800 & 800 & 1200 \\
Specific weight per unit fabric area & $\mathrm{g} / \mathrm{m}^{2}$ & 200 & 160 & 300 \\
Fabric specific weight & $\mathrm{g} / \mathrm{cm}^{3}$ & 1.78 & 1.78 & 2.50 \\
Grid spacing (square grid side) & $\mathrm{mm}$ & 8 & 5 & 12 \\
Fabric cross-sectional area (per unit width), $A_{f}$ & $\mathrm{~mm}^{2} / \mathrm{cm}$ & 0.56 & 0.88 & 0.60 \\
Ultimate strength along the principal direction (with epoxy) & $\mathrm{N} / \mathrm{cm}$ & 1800 & 1800 & 720 \\
Elastic modulus & $\mathrm{GPa}$ & 240 & 240 & 74 \\
\hline
\end{tabular}

Table 2: Fabric mechanical properties $(1$ tex $=9$ den $)$

bi-axial (for traction tests, coded C1) or uni-axial (for bending tests, coded C2) open square-grid high-tenacity (HT) fabric, see Figs.1(a) and (b), respectively. Glass reinforcement is a bi-axial open square-grid fabric with a $19 \%$ weight content of $\mathrm{ZrO}_{2}$ (Zirconium dioxide or Zirconia) to impart alkali resistance, Fig.1(c).

\subsection{Silica nano-coating}

$\mathrm{SiO}_{2}$-coated fibres are prepared through sol-gel synthesis as reported by [24]. First, tetraethyl orthosilicate (98\% TEOS(C), Sigma-Aldrich Inc.) and isopropyl alcohol ( $\geq 99.7 \%$ Sigma-Aldrich Inc.) are mixed together for $15 \mathrm{~min}$ and then deionized water and nitric acid (65\% Carlo Erba Reagents Srl) are added. This solution is further stirred for $2 \mathrm{hrs}$ in a magnetic stirrer. The solution TEOS: $\mathrm{C}_{3} \mathrm{H}_{7} \mathrm{OH}: \mathrm{H}_{2} \mathrm{O}: \mathrm{HNO}_{3}$ is in the molar ratio $1: 4.5: 5: 0.16$. Coating is realized through bathing fibers in the obtained solution for $5 \mathrm{~min}$, to ensure that the whole fiber surface is thoroughly wetted. After bathing, fibers are air-dried at room temperature for $12 \mathrm{hrs}$ and then at $110^{\circ} \mathrm{C}$ for $15 \mathrm{~min}$ in an oven.

\subsection{Specimen configurations}

\subsubsection{Uni-axial tensile test}

Two reinforcement materials, namely AR-Glass and bi-axial carbon fabric (C1), are investigated and, for each of these, three test groups are considered, namely dry-fabric (alias uncoated), silica coated and polymer coated fabric. Six prismatic coupons are manufactured in each test group for a total of 36 coupons. 


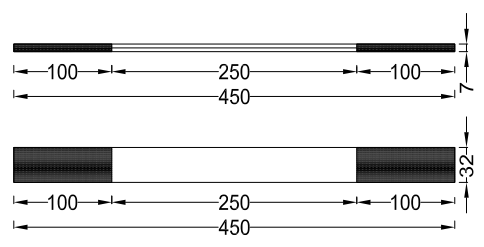

Figure 2: TRM coupon geometry

Coupon geometry is illustrated in Fig.2. Specimens conform to the specifications of Annex A of [7] and, in particular, the coupon nominal width is chosen as a multiple of the fabric grid spacing [7, §A3.0]. Thus, with respect to ARG fabric reinforced specimens, the coupon width $w_{s, G}=360 \mathrm{~mm}$ accommodates 3 strands, while, for carbon fabric reinforced specimens, the coupon width $w_{s, C}=$ $320 \mathrm{~mm}$ accommodates 4 strands.

Specimens are manufactured on an individual basis, in order to avoid cutting from a larger sheet $[7, \mathrm{~A} 1.0]$. To this aim, a modular polyethylene formwork is adopted to ensure consistent placing of the fabric at the specimen mid-plane. Besides, after 7-day moist-curing, the formwork is disassembled to ease sample stripping. The manufacturing process consists of the following steps:

1. formwork is spray-lubricated with silicon oil;

2. a 3-mm-thick mortar layer is cast onto the bottom piece of the formwork and levelled up to the formwork brim with a scraper (Fig.3a);

3 . in the case of polymer coated specimens, fabric impregnation is obtained through immersion of the cut-to-size fabric patch, which is then squeezed out to remove the excess of resin (see also [6]). It is important to observe that impregnated fabric allows a restricted 15-30 min time-frame for effective application, before resin catalysis completes;

4. cut-to-size fabric reinforcement is laid and gently pressed on top of the mortar layer (Fig.3b); air bubbles are eliminated through rolling;

5. the upper piece of the formwork is installed and it constraints the reinforcement fabric at the specimen mid-plane;

6. a 3-mm-thick mortar over-layer is set and levelled up to the surmounting formwork with a scraper (Fig.3c).

7. specimens are moist-cured (conditioning) in a polypropylene bag for 7 days as prescribed in $[7$, A5.0].

After conditioning, the formwork is dismounted and specimens are stripped (Fig.3d) for curing at the laboratory conditions $\left(21 \pm 2^{\circ} \mathrm{C}\right.$ and $60-75 \%$ relative humidity). The total conditioning and curing time is 28 days. Finally, coupons are fitted with 100-mm-long carbon fabric tabs, which are glued at both ends through epoxy resin. 


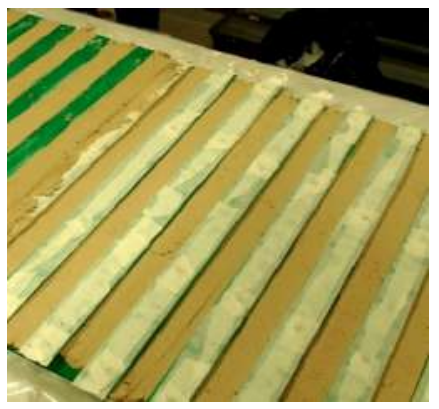

(a)

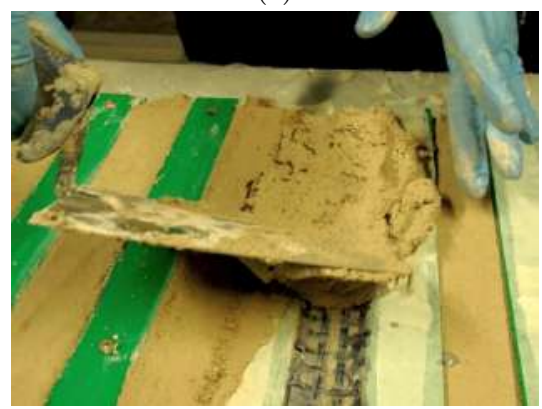

(c)

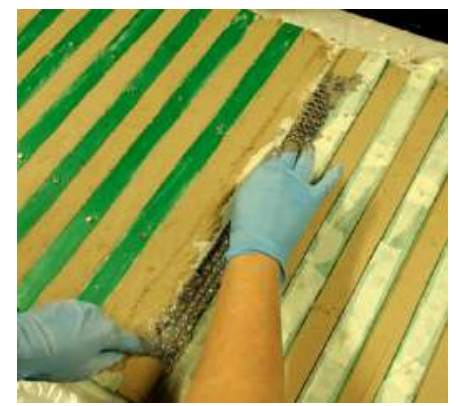

(b)

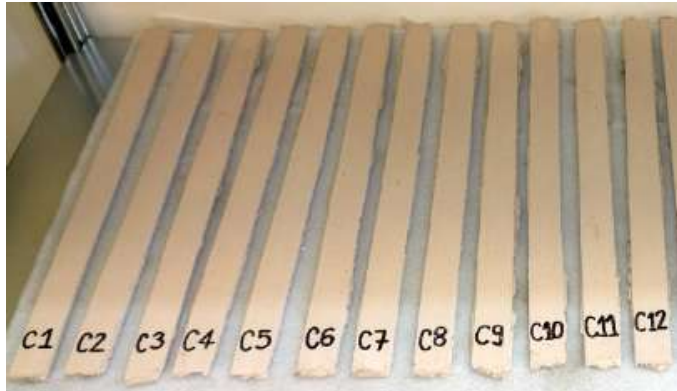

(d)

Figure 3: Specimen manufacturing: formwork and first mortar layer (a), carbon fabric placement (b), mortar over-layer being set in the top formwork (c) and stripped coupon after moist-curing (d) 


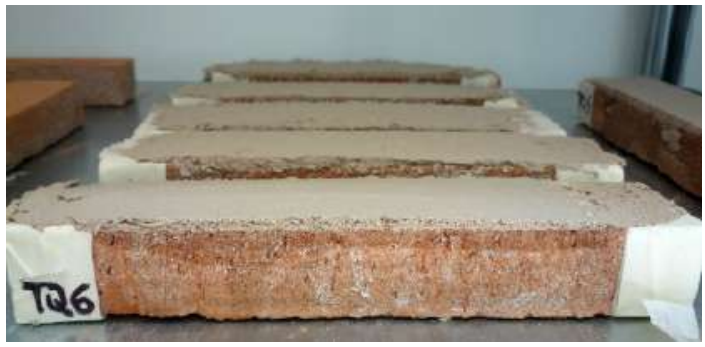

Figure 4: ARG TRM laminated brick specimens

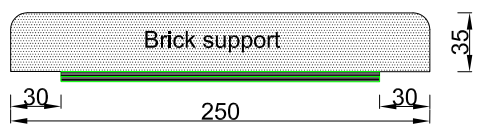

Figure 5: Three-point bending of laminated bricks schematic

\subsubsection{Three-point bending tests}

Three-point bending tests are performed on clay bricks following [25]. Bricks are strengthened at the bottom surface by lamination of TRM composite material, see Fig.4. This strengthening material belongs to one out of six test groups, corresponding to those already considered in uni-axial traction, namely AR-Glass and Carbon reinforcing fabric and, for each of these, dry-fabric, silica coated and polymer coated fabric. Again, 6 laminated bricks are considered for each test group.

The lamination geometry is illustrated in Fig.5 and it appears that no provision against delamination is taken at the specimen ends. Indeed, the adopted mortar has already proven very effective in terms of bond formation with a clay substrate, see [6]. Fig.6 shows the clay brick substrate (Fornace Brioni Srl). In particular, the brick mean strength curve under three-point bending is presented in Fig.7.

Lamination is performed according to the following procedure:

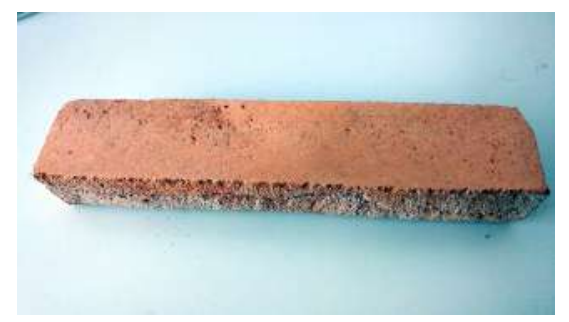

Figure 6: Clay brick, which is used as lamination substrate for three-point bending test 


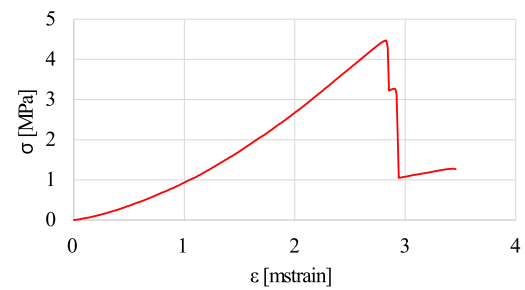

Figure 7: Mean strength curve of the clay brick (prior to lamination)

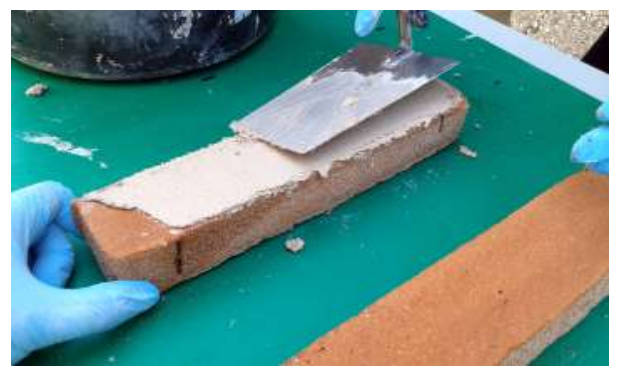

Figure 8: Brick lamination: the first mortar layer is laid on the wetted specimen surface

1. the brick surface is levelled (yet surface should remain rough) and thoroughly wetted to warrant complete mortar-to-clay bond formation;

2. paper adhesive tape is located at the brick ends to protect the supported zone from the lamination material (Fig.4);

3. a 1-mm-thick layer of mortar is laid on the wetted brick surface. Levelling the brick surface averts the risk of obtaining areas where the laminate is excessively thick, which is undesirable on account of the small scale of the test (Fig.8);

4. for polymer coating, impregnation takes place as for coupon manufacture;

5. cut-to-size fabric is laid and slightly pressed onto the fresh mortar. Air bubbles trapped at the mortar-to-fabric interface are eliminated through rolling;

6. a 3-mm-thick over-layer of mortar is applied and levelled by using a scraper.

A removable formwork provides a smooth and regular border for lamination. Conditioning and curing take place as per uni-axial traction tests (28 days on the overall). 


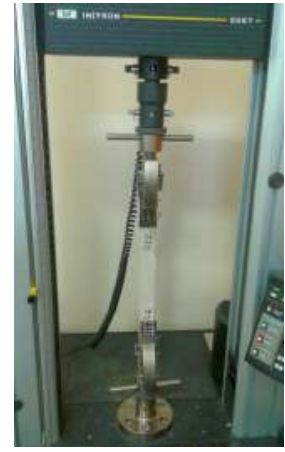

(a)

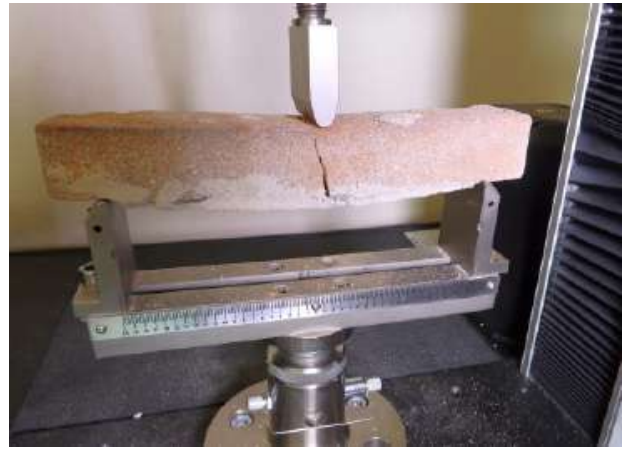

(b)

Figure 9: Test set-ups: (a) uni-axial tensile test (b) three-point bending test (support distance $d=200 \mathrm{~mm})$

\section{Experimental investigation}

\subsection{Uni-axial tensile test}

Coupons are tested under displacement control in an Instron 5567 electromechanical uni-axial testing machine, equipped with a $30 \mathrm{kN}$ load cell. Traction occurs at a constant nominal elongation rate of $0.5 \mathrm{~mm} / \mathrm{min}$ which, as prescribed by [26], amounts to an imposed elongation rate of about $2 \mathrm{mstrain} / \mathrm{min}$. The testing machine is equipped with pneumatic wedge grips connected to the crosshead through a spherical hinge. The test set-up is shown in Fig.9(a).

A stereoscopic twin-camera 3 Mpixel Dantec Dynamics Q-400 Digital Imaging Correlation (DIC) system is adopted to capture the displacement field of the specimen surface, previously speckled, throughout the test. DIC investigation allows correcting the displacement ramp prescribed at the traction machine crosshead by the elongation taking place at the wedge grips and thus it provides the actual specimen deformation. This step is mandatory for a reliable evaluation of the ultimate strain [27]. Indeed, Fig.10 compares the specimen elongation for ARG coupons in the uncoated, silica and polymer coated groups with the prescribed ramp. Regression lines are shown together with the coefficient of determination $R^{2}$. It immediately appears that the regression line for silica coated specimens almost coincides with the corresponding regression line belonging to the polymer coated group.

\subsection{Three-point bending test}

Three-point bending is carried out in the same Instron 5567 electromechanical machine, now equipped with a two-point support and a floating knife. The test set-up is shown in Fig.9(b). Bending test occurs under displacement control at $1 \mathrm{~mm} / \mathrm{min}$ speed for the moving knife [25]. 


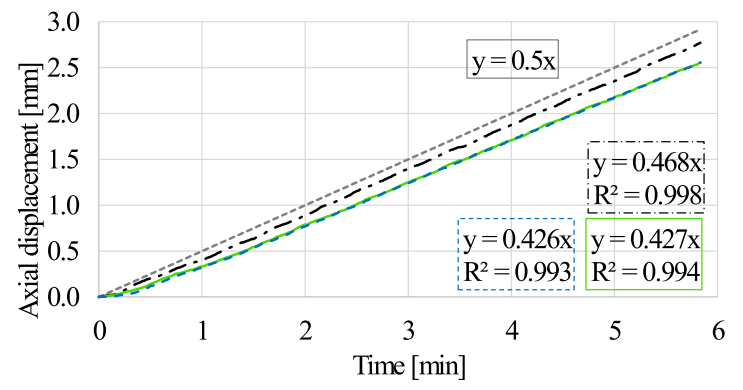

Figure 10: DIC estimated vs. prescribed (grey, short-dashed line) specimen end displacement curves for ARG coupons: uncoated (black, dash-dot), silica (green, solid line) and, almost superposed, polymer coated (blue, dashed line)

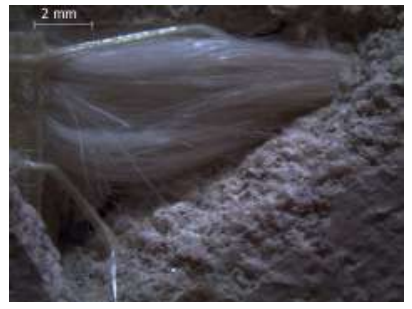

(a)

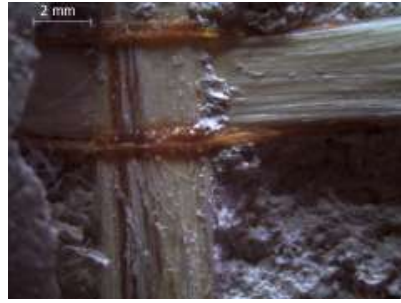

(b)

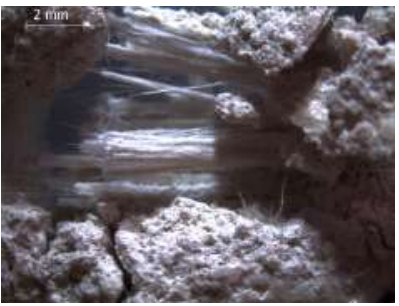

(c)

Figure 11: Optical microscopy investigation at 8X magnification of ARG failed specimens (a) uncoated (b) silica and (c) polymer coated

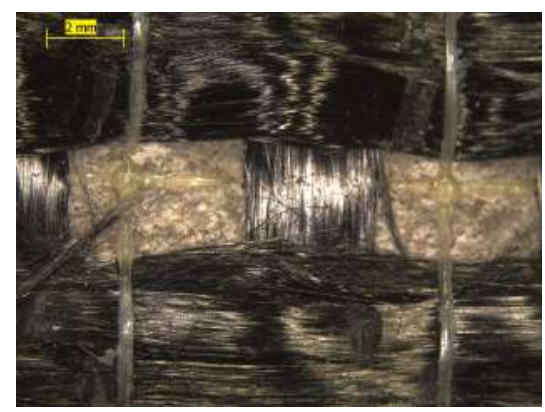

(a)

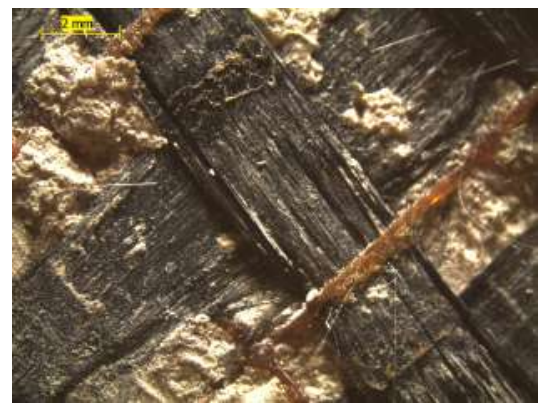

(b)

Figure 12: Optical microscopy investigation at $8 \mathrm{X}$ magnification of $\mathrm{C} 1$ failed specimens (a) uncoated (b) silica coated 


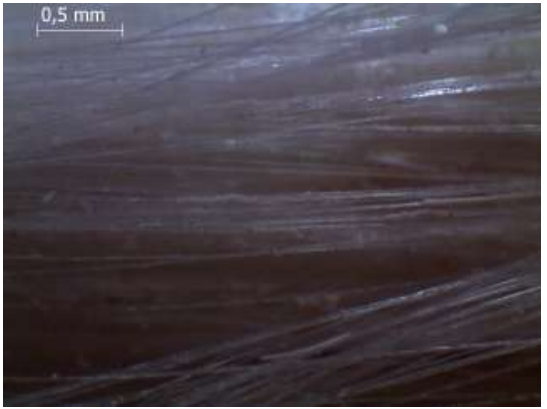

(a)

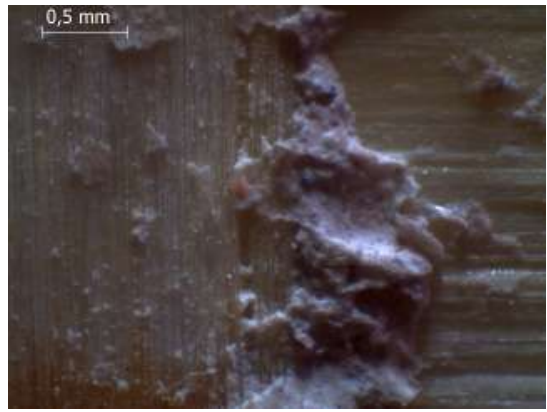

(b)

Figure 13: Optical microscopy investigation at 35X magnification of ARG failed specimens (a) untreated (b) silica coated

\subsection{Optical and scanning microscope investigation}

In consideration of the strong connection between mechanical properties of the composite and interphase compatibility, a visual analysis is conducted using both optical and scanning electron microscopy (SEM). This analysis falls in line with the conditions of acceptance given in [7, §4.5.2]. Figs.11 and 12 show the fabric surface after failure at $8 \mathrm{X}$ magnification, respectively for ARG and $\mathrm{C} 1$ specimens. It appears that uncoated specimens show no evidence of mortar adhesion to the fabric surface, whereas silica and, even more so, polymer coated specimens present patches still bonded to the matrix. To better illustrate the point, Fig.13 presents a 35X comparison between uncoated and silica coated ARG failed specimens. It is seen that the silica coated specimen shows clear evidence of interphase bond enhancement and strong bond formation with the matrix. Conversely, the lime-based matrix possesses little compatibility with the uncoated fabric from which it detaches completely at failure, leaving an almost perfectly polished surface. In fact, in the lack of chemical adhesion, the major contribution to mechanical performance is given by the mechanical interlock occurring through the open square grid of the fabric. Similar observations are suggested by a SEM investigation at 1000X magnification for a C1 failed specimen (Fig.14). It can be observed that, for the uncoated specimen, only a few outmost fabric strands are adhered to by the mortar, whereas for silica coated and, to an even greater extent, for polymer coated specimens, uniformly diffuse bond formation appears.

\section{Results and discussion}

\subsection{Carbon fabric}

Fig.15 gathers the mean stress-strain curves and the confidence bands (i.e. mean stress-strain curve \pm one-standard deviation) for uni-axial traction of $\mathrm{C} 1$ coupons in all test groups. Force is conventionally reported to the fabric crosssectional area $[7,18]$. Mean ultimate strength and strain are determined and 


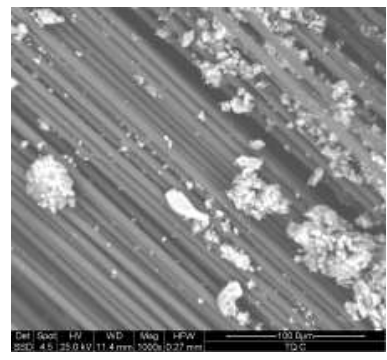

(a)

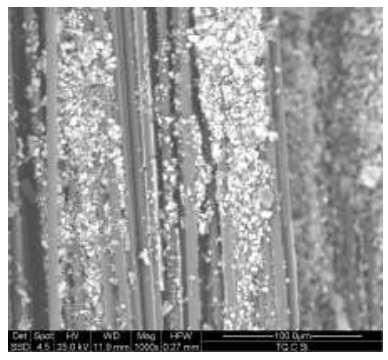

(b)

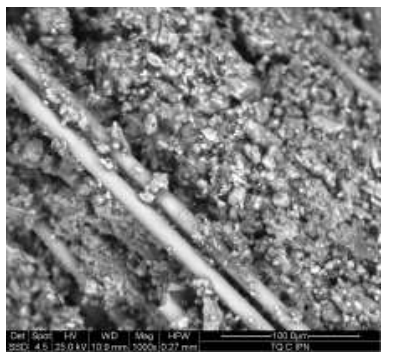

(c)

Figure 14: SEM investigation of $\mathrm{C} 1$ failed specimens at 1000X magnification: (a) uncoated (b) silica and (c) polymer coated

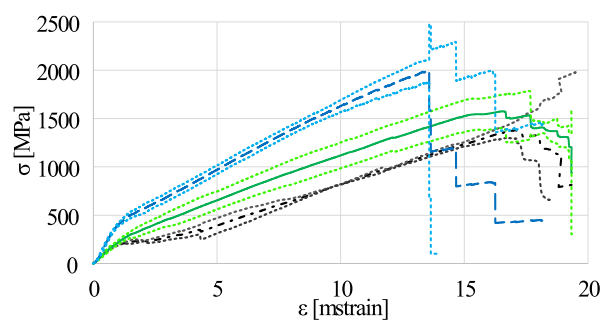

Figure 15: Mean stress-strain curves for uni-axial traction of C1 uncoated (black, dash-dotted) silica (green, solid) and polymer coated (blue, dashed) specimens. Confidence bands, in terms of $\mu \pm S D$, are also given (dotted) 


\begin{tabular}{|c|c|c|c|c|c|c|}
\hline Group & $\begin{array}{c}\mu\left(f_{f u, t}\right) \\
{[\mathrm{MPa}]}\end{array}$ & $S D_{f}$ & $C V_{f}$ & $\mu\left(\epsilon_{f u, t}\right)$ & $S D_{\epsilon}$ & $C V_{\epsilon}$ \\
\hline UC & 1496 & 245 & 16 & 2.23 & 0.46 & 20 \\
SC & 1637 & 180 & 11 & 2.07 & 0.10 & 5 \\
PC & 2117 & 92 & 4 & 1.52 & 0.19 & 13 \\
\hline
\end{tabular}

Table 3: Mean ultimate tensile strength $\mu\left(f_{f u, t}\right)$ and elongation $\mu\left(\epsilon_{f u, t}\right)$, together with corresponding standard deviation, $S D$, and coefficient of variation, $C V$, for uncoated (UC), silica (SC) and polymer coated (PC) C1 specimens in uni-axial traction

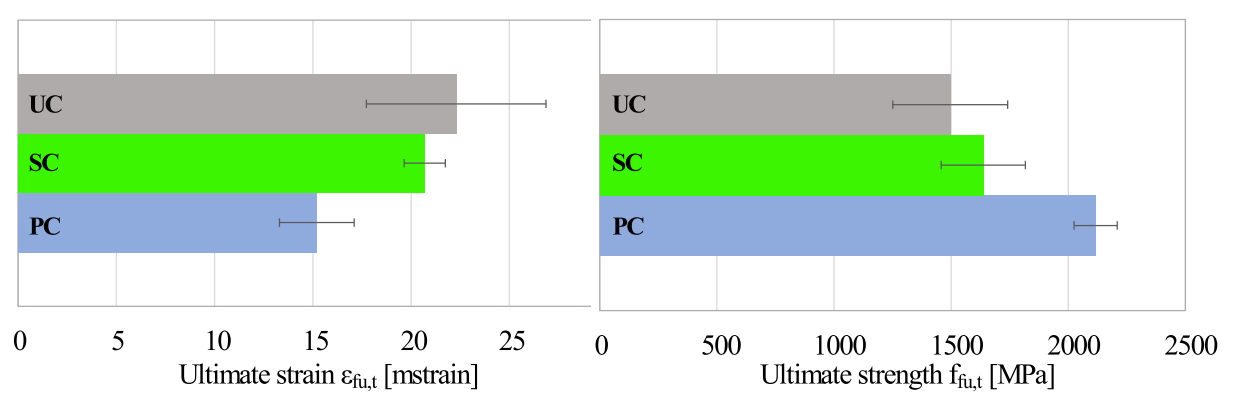

(a)

(b)

Figure 16: Mean ultimate strain (a) and strength (b) for $\mathrm{C} 1$ coupons in uni-axial traction: uncoated (UC) silica (SC) and polymer coated (PC)

they are collected in Tab.3 along with the standard deviation, $S D$, and the coefficient of variation, $C V$ (also known as relative standard deviation).

Fig.16 presents a bar-chart comparison of mean ultimate values for all $\mathrm{C} 1$ groups tested in traction. It is observed that, although silica coating offers a mere $10 \%$ mean ultimate strength increase over the uncoated group, it conveys a $26 \%$ reduction of the standard deviation. This decrease of data dispersion is even more pronounced when expressed in terms of ultimate strain. Indeed, ultimate strain is reduced by $7 \%$ with respect to the uncoated group and yet the corresponding standard deviation is decreased by an impressive $78 \%$, i.e. it is reduced to one fourth. Therefore, it appears that silica coated specimens become marginally stronger and more brittle than uncoated ones, however failure occurs consistently in terms of ultimate strain, which behaviour conveys a strong beneficial effect on design values. Indeed, according to [7], the ultimate strain is obtained by the so-called three-sigma rule,

$$
\epsilon_{f u}=\mu\left(\epsilon_{f u, t}\right)-3 S D_{\epsilon},
$$

from which the design strain follows

$$
\epsilon_{f d}=0.7 \epsilon_{f u}<1.2 \% .
$$

From Tab.3, it is $\epsilon_{f u}=0.85 \%$ for the uncoated group and $\epsilon_{f u}=1.77 \%$ for the silica coated group, that gives a two-fold increase. Similarly, if characteristic 


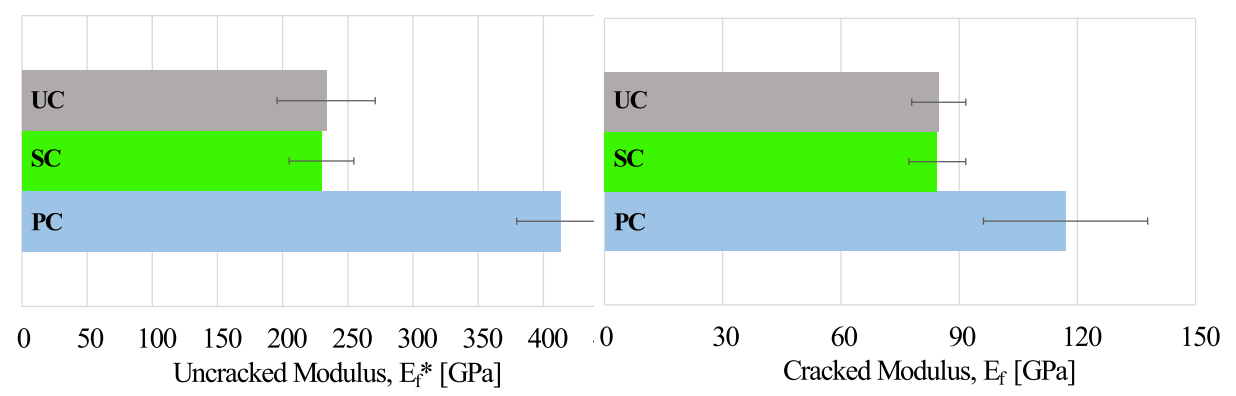

(a)

(b)

Figure 17: Uncracked (a) and cracked modulus (b) for C1 coupons in uni-axial traction: uncoated (UC) silica (SC) and polymer coated (PC)

values are considered as the basis from which design strain is determined (see the design considerations in [18])

$$
\epsilon_{f u k}=\mu\left(\epsilon_{f u, t}\right)-1.96 S D_{\epsilon},
$$

we find $\epsilon_{f u k}=1.33 \%$ for the uncoated and $\epsilon_{f u k}=1.87 \%$ for the silica coated group, which still brings a $41 \%$ increment. This substantial gain in the design strain reflects itself in an equally important benefit in terms of design strength, for the latter is proportional to the former through $E_{f}$, the tensile modulus of elasticity of the cracked composite material $[7, \S 8]$.

Results for polymer coated specimens give a $42 \%$ and a $29 \%$ improvement of the mean ultimate strength over the uncoated and the silica coated groups, respectively. Such strength increment is accompanied by an impressive decease in the coefficient of variation, that is reduced to one-fourth of that pertaining to uncoated specimens. However, strength gain comes at a significant cost in terms of ductility, for mean ultimate strain is reduced by $32 \%$ as compared to the uncoated group.

In terms of design values, we have $\epsilon_{f u}=0.95 \%$, which brings a small $11 \%$ increase over uncoated specimens, and yet it is nearly half the corresponding value for silica coating. Besides, when characteristic values are adopted, we find $\epsilon_{f u k}=1.15 \%$, which is lower than the corresponding value in the uncoated group. It is concluded that, under the light of best design values, silica coating offers better performance over polymer coating.

Values of the cracked and of the uncracked moduli are presented in Tab.4 together with transition point locations. It is interesting to note that, for the uncoated and for the silica coated groups, uncracked and cracked moduli are nearly equal, whereas polymer coated specimens are substantially stiffer (Fig.17). This observation highlights the importance of interphase bond formation in determining tensile moduli. Transition points are determined as in [16] and they are plotted in Fig.18 along with confidence bars. In particular, it can be seen that the transition point for uncoated specimens is located in the third quadrant of the $(\sigma, \epsilon)$ plane. 


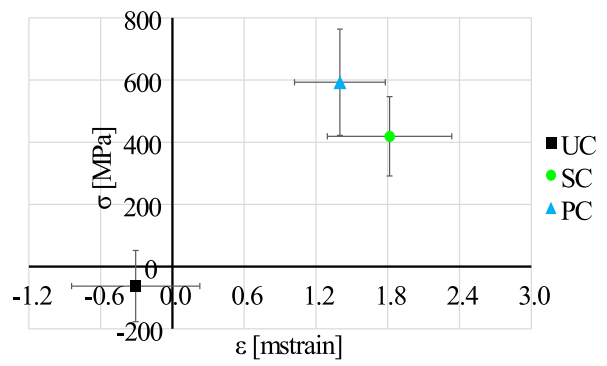

Figure 18: Transition point location and standard deviation bars for $\mathrm{C} 1$ coupons in uni-axial traction: uncoated (UC) silica (SC) and polymer coated (PC)

\begin{tabular}{|c|c|c|c|c|c|c|c|c|}
\hline Group & $E_{f}^{*}$ & $S D_{E_{f}^{*}}$ & $\begin{array}{c}E_{f} \\
\text { Da] }\end{array}$ & $S D_{E_{f}}$ & $\begin{array}{l}\epsilon_{T} \\
{[\mathrm{~ms}}\end{array}$ & $\begin{array}{l}S D_{\epsilon} \\
\text { ain] }\end{array}$ & $f_{T}$ & $\begin{array}{l}S D_{f_{T}} \\
\mathrm{~Pa}]\end{array}$ \\
\hline UC & 233 & 34 & 85 & 7 & -0.3 & 0.5 & -63 & 115 \\
\hline $\mathrm{SC}$ & 230 & 25 & 84 & 7 & 1.8 & 0.5 & 419 & 128 \\
\hline $\mathrm{PC}$ & 413 & 33 & 117 & 21 & 1.4 & 0.4 & 593 & 171 \\
\hline
\end{tabular}

Table 4: Uncracked modulus, $E_{f}^{*}$, cracked modulus, $E_{f}$, and turning point location with corresponding standard deviations for uncoated (UC), silica (SC) and polymer coated (PC) $\mathrm{C} 1$ specimens in uni-axial traction

Mean stress-strain curves and confidence bands for three-point bending of C2 coupons are presented in Fig.19. It is observed that confidence bands are considerably narrower in the uncoated and in the silica groups compared to the polymer coated group and this occurs for strain and strength alike. On the other hand, unlike traction, mean curves show remarkable correspondence until failure occurs. Tab.5 shows the mean ultimate values as determined through threepoint bending tests. In contrast to traction, the coefficient of variation $C V_{f}$, relative to the ultimate mean strength of silica coated specimens in bending, is roughly one fifth than that for polymer coated specimens. The corresponding quantity relative to the ultimate strain, $C V_{\epsilon}$, is $38 \%$ less than for polymer

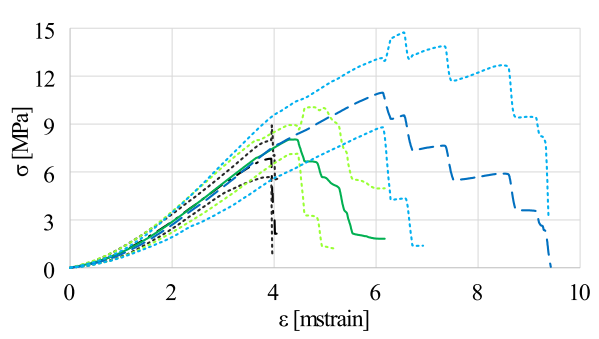

Figure 19: Mean stress-strain curve for three-point bending of C2 uncoated (black, dashdotted) silica (green, solid) and polymer coated (blue, dashed) specimens. Confidence bands, in terms of $\mu \pm S D$, are also given (dotted) 


\begin{tabular}{|c|c|c|c|c|c|c|c|}
\hline Group & \multicolumn{2}{|c|}{$\mu\left(f_{u, f}\right)$} & $S D_{f}$ & $C V_{f}$ & $\mu\left(\epsilon_{u, f}\right)$ & $S D_{\epsilon}$ & $C V_{\epsilon}$ \\
& \multicolumn{2}{|c|}{$[\mathrm{MPa}]$} & \multicolumn{4}{|c|}{$[\%]$} \\
\hline UC & 6.95 & 1.20 & 17 & 0.41 & 0.03 & 7 \\
SC & 8.62 & 0.36 & 4 & 0.57 & 0.07 & 12 \\
PC & 12.70 & 2.42 & 19 & 0.80 & 0.16 & 20 \\
\hline
\end{tabular}

Table 5: Mean ultimate flexural strength $\mu\left(f_{u, f}\right)$ and elongation $\mu\left(\epsilon_{u, f}\right)$, together with corresponding standard deviation, $S D$, and coefficient of variation, $C V$, for uncoated (UC), silica (SC) and polymer coated (PC) C2 specimens in three-point bending of laminated clay bricks

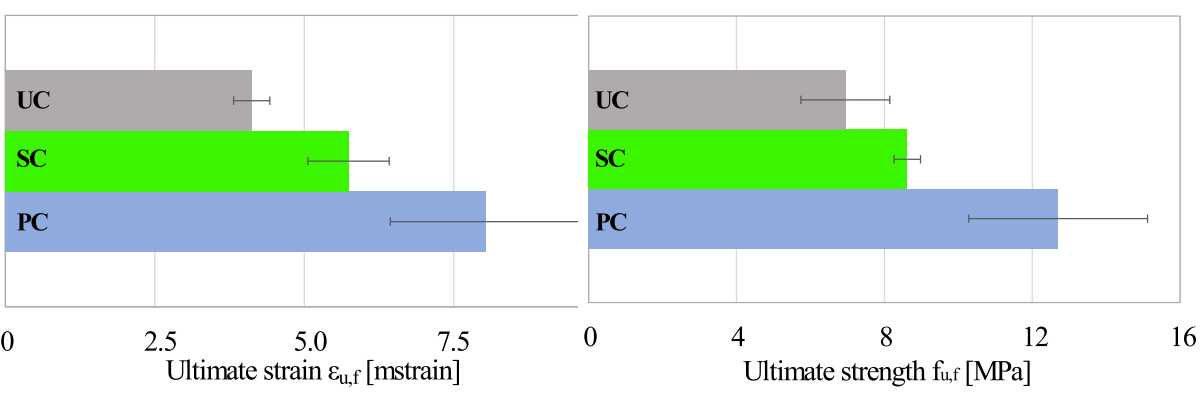

(a)

(b)

Figure 20: Mean ultimate strain (a) and strength (b) for C2 laminated bricks in three-pointbending: uncoated (UC), silica (SC) and polymer coated (PC)

coated specimens, yet $68 \%$ grater than in the uncoated group. However, this apparently surprising outcome is expected, owing to the uncertainty connected to the determination of the ultimate deformation at failure of ductile, as opposed to brittle, specimens. Finally, Fig.20 gives a bar-chart illustration of ultimate strength and strain obtained in bending for all test groups.

\subsection{AR-Glass fibres response}

Fig.21 presents the mean stress-strain curves for uni-axial traction of ARG coupons in all test groups. The corresponding ultimate stress and strain values are given in Tab.6.

\begin{tabular}{|c|c|c|c|c|c|c|c|}
\hline Groups & $\begin{array}{c}\mu\left(f_{f u, t}\right) \\
{[\mathrm{MPa}]}\end{array}$ & $S D_{f}$ & $C V_{f}$ & $\mu\left(\epsilon_{f u, t}\right)$ & $S D_{\epsilon}$ & $C V_{\epsilon}$ \\
\hline UC & 353 & 33 & 9 & 1.13 & 0.22 & 20 \\
SC & 786 & 74 & 9 & 1.96 & 0.11 & 6 \\
PC & 1042 & 47 & 4 & 2.31 & 0.19 & 8 \\
\hline
\end{tabular}

Table 6: Mean ultimate tensile strength $\mu\left(f_{f u, t}\right)$ and elongation $\mu\left(\epsilon_{f u, t}\right)$, together with corresponding standard deviation, $S D$, and coefficient of variation, $C V$, for uncoated (UC), silica (SC) and polymer coated (PC) ARG specimens in uni-axial traction 


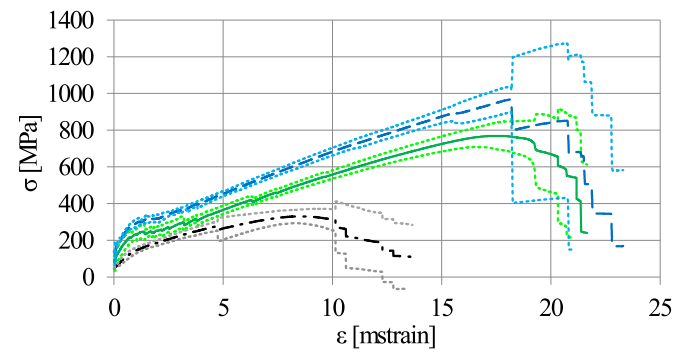

Figure 21: Mean stress-strain curves for uni-axial traction of ARG uncoated (black, dashdotted) silica (green, solid) and polymer coated (blue, dashed) specimens. Confidence bands, in terms of $\mu \pm S D$, are also given (dotted)

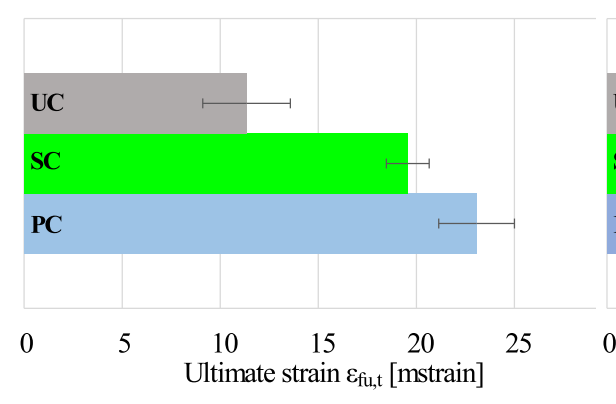

(a)

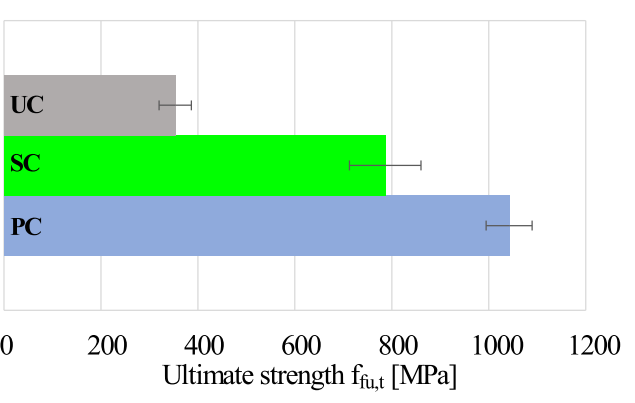

(b)

Figure 22: Mean ultimate strain (a) and mean ultimate strength (b) for ARG specimens in uni-axial traction: uncoated (UC) silica (SC) and polymer coated (PC) 


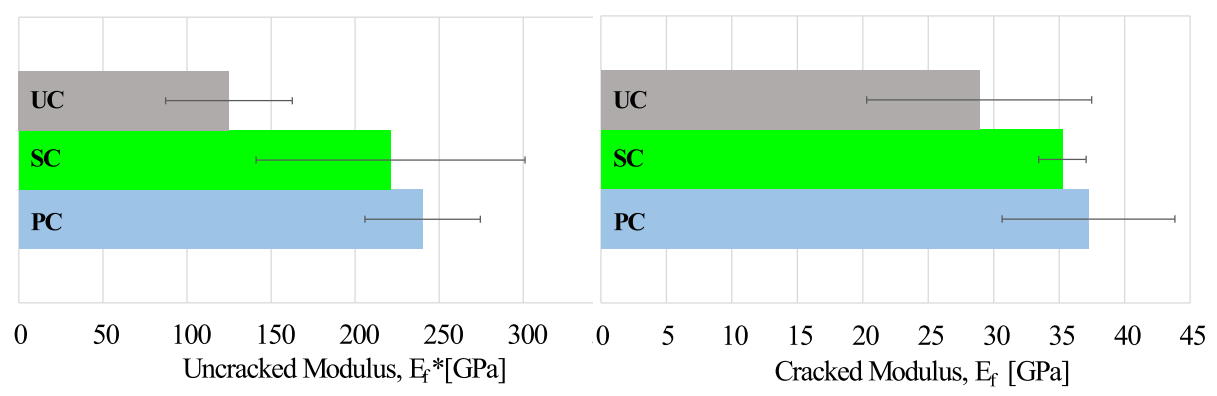

(a)

(b)

Figure 23: Uncracked (a) and cracked modulus (b) for ARG coupons in uni-axial traction: uncoated (UC) silica (SC) and polymer coated (PC)

The bar-chart comparison of Fig.22 indicates that silica and polymer coating of ARG induce a strong beneficial effect on the ultimate strength which, unlike carbon fabric, comes along with a relevant ductility increment. However, confidence bars still confirm that the best performance in terms of design strain is achieved by silica coating. Indeed, by Eq.(1), we have $\epsilon_{f u}=0.47 \%$ for the uncoated group and $\epsilon_{f u}=1.63 \%$ for the silica coated group, that is nearly a 3.5 -fold increase, to be compared with 2.2 -fold increase in the ultimate strength. For polymer coated specimens, we get $\epsilon_{f u}=1.74 \%$, which is similar to the performance of the silica coated group (in fact, it displays a $6.7 \%$ increment), and it should be contrasted with $295 \%$ and $135 \%$ increments in terms of ultimate strength, with respect to the uncoated and the silica coated groups, respectively. When characteristic values are referred to, we get, according to Eq.(3), $\epsilon_{f u k}=0.70 \%, 1.74 \%$ and $1.93 \%$, respectively for the uncoated, silica and polymer coated groups. Surprisingly, while adopting characteristic values, as opposed to the three-sigma-rule, has a marked effect on the design strain in the uncoated group, it determines little change on the design values of silica and polymer coated groups, the latter surpassing the former by $11 \%$. These considerations show that the remarkable increment that polymer coating imparts on the ultimate strength, as compared to silica coating, is not matched by a parallel increment in design values, which, in fact, are very similar, whether they be calculated through the three-sigma-rule or through characteristic values. Conversely, the important ultimate strength increment obtained by silica coated specimens over uncoated ones appears even more pronounced when looked at in terms of design values. As a result, for designing purposes, polymer coating is equivalent to silica coating.

Tab.7 gathers uncracked and cracked moduli, turning point location and corresponding standard deviations. Fig.23 presents a bar-chart comparison of uncracked and cracked moduli for ARG coupons, while Fig.24 illustrates the turning point location with confidence bars.

Fig.25 presents the mean strength curves for ARG laminated bricks in threepoint bending tests and Tab. 8 gathers the mean ultimate strength and strain 


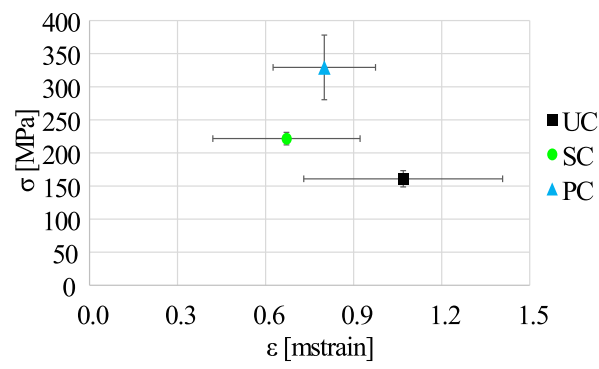

Figure 24: Transition point location and confidence bars for ARG coupons in uni-axial traction: uncoated (UC) silica (SC) and polymer coated (PC)

\begin{tabular}{|c|c|c|c|c|c|c|c|c|}
\hline Group & $E_{f}^{*}$ & $S D_{E_{f}^{*}}$ & $\begin{array}{l}E_{f} \\
\text { a] }\end{array}$ & $S D_{E_{f}}$ & $\begin{array}{l}\epsilon_{T} \\
{[\mathrm{~ms}}\end{array}$ & $\begin{array}{c}S D_{\epsilon} \\
\text { cain] }\end{array}$ & $f_{T}$ & $\begin{array}{l}S D_{f_{T}} \\
\mathrm{~Pa}]\end{array}$ \\
\hline$\overline{\mathrm{UC}}$ & 125 & 38 & 29 & 9 & 1.1 & 0.3 & 161 & 12 \\
\hline $\mathrm{SC}$ & 221 & 80 & 35 & 2 & 0.7 & 0.3 & 222 & 9 \\
\hline $\mathrm{PC}$ & 240 & 34 & 37 & 7 & 0.8 & 0.2 & 329 & 49 \\
\hline
\end{tabular}

Table 7: Uncracked modulus, $E_{f}^{*}$, cracked modulus, $E_{f}$, and turning point location with corresponding standard deviations for uncoated (UC), silica (SC) and polymer coated (PC) ARG specimens in uni-axial traction

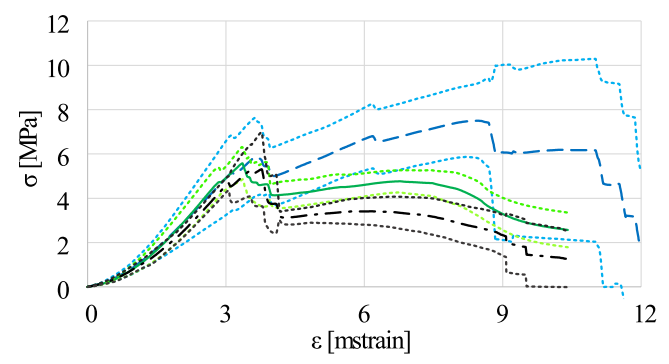

Figure 25: Mean stress-strain curves for three-point bending tests of ARG uncoated (black, dash-dotted) silica (green, solid) and polymer coated (blue, dashed) specimens. Confidence bands, in terms of $\mu \pm S D$, are also given (dotted)

\begin{tabular}{|c|c|c|c|c|c|c|}
\hline Group & $\begin{array}{c}\mu\left(f_{u, f}\right) \\
{[\mathrm{MPa}]}\end{array}$ & $S D_{f}$ & $C V_{f}$ & $\mu\left(\epsilon_{f u}\right)$ & $\sigma_{\epsilon}$ & $C V_{\epsilon}$ \\
\hline UC & 6.06 & 0.80 & 13 & 0.87 & 0.26 & 30 \\
SC & 6.10 & 0.40 & 6 & 1.00 & 0.07 & 7 \\
PC & 8.54 & 1.31 & 15 & 1.13 & 0.21 & 19 \\
\hline
\end{tabular}

Table 8: Mean ultimate flexural strength $\mu\left(f_{u, f}\right)$ and elongation $\mu\left(\epsilon_{u, f}\right)$, together with corresponding standard deviation, $S D$, and coefficient of variation, $C V$, for uncoated (UC), silica (SC) and polymer coated (PC) ARG specimens in three-point bending of laminated clay bricks 


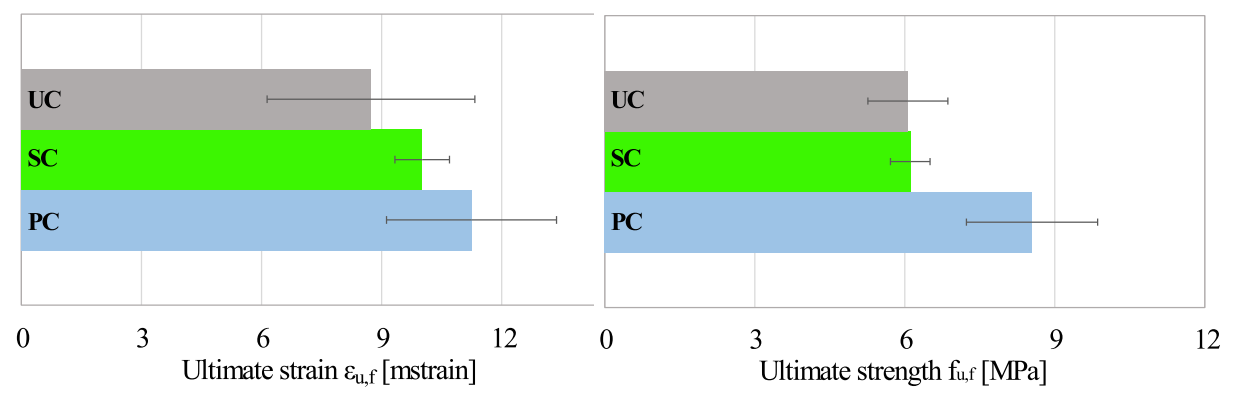

(a)

(b)

Figure 26: Mean ultimate strain (a) and strength (b) for ARG laminated bricks in threepoint-bending: uncoated (UC), silica (SC) and polymer coated (PC)

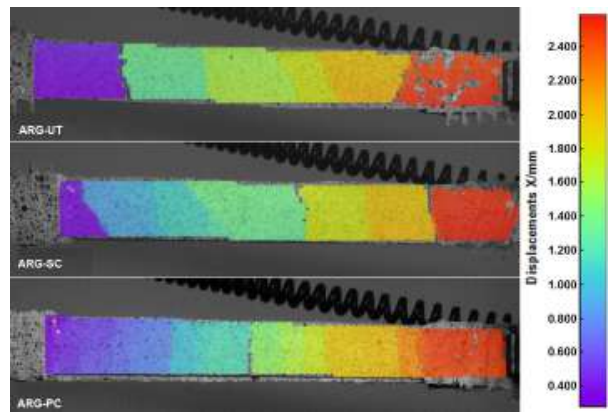

Figure 27: Longitudinal displacement field for ARG coupons at $\epsilon=10$ mstrain (from top to bottom: uncoated, silica and polymer coated)

values determined accordingly. As expected, bending test results are more homogeneous across groups as compared to tensile tests. However, the result is retrieved that the standard deviation, and the coefficient of variation alike, associated with silica coated specimens, is the lowest among groups. Fig.26 present in bar-chart form ultimate strength and strain values as determined in bending for ARG laminated bricks.

\subsection{Crack pattern and dissipated energy}

The quality of interphase bond strength may be assessed through the analysis of the crack pattern evolution prior to failure and of the energy dissipated in crack formation and widening $[28,18]$. Fig. 27 presents a DIC colour map display of ARG coupons longitudinal displacement field at $\epsilon=10$ mstrain. Clearly, the displacement field is roughly piecewise constant and the number of uniformly coloured patches is strictly related to the crack density. Fig.28 plots the evolution of the average crack spacing against the specimen elongation for ARG test groups. Similarly, Fig.29 describes the average crack width against the specimen elongation. It can be observed that uncoated specimens display the largest 


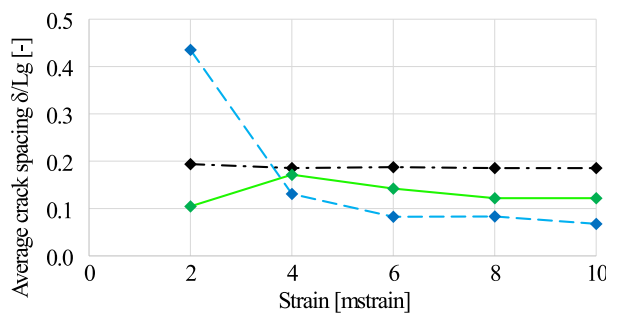

Figure 28: Average crack spacing vs. elongation $\epsilon$ for ARG specimens belonging to the uncoated (black, dash-dotted curve) silica (green, solid curve) and polymer coated (light blue, dashed curve) groups

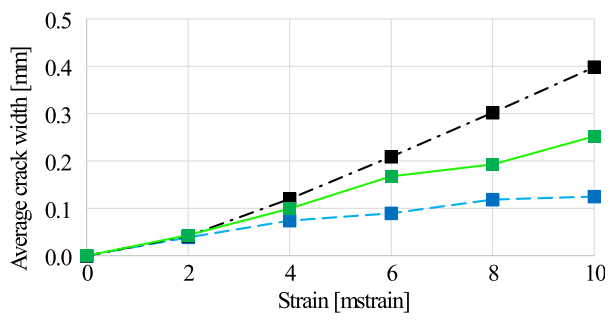

Figure 29: Average crack width vs. elongation $\epsilon$ for ARG specimens belonging to the uncoated (black, dash-dotted curve) silica (green, solid curve) and polymer coated (light blue, dashed curve) groups

crack spacing and the widest crack opening at (almost) all elongations. Indeed, crack width appears remarkably constant and crack spacing grows almost linearly with the elongation. In contrast, polymer coated specimens present diffuse and thin cracking (with the possible exception of the very early stage of deformation, when the effect of the gripping system is more evident), which slowly widens with the elongation. Silica coated specimens behave halfway in between the two groups. These plots provide evidence of interphase bond strengthening and, in fact, they may be used as a mean to assess this enhancement.

Fig.30 compares energy dissipation, evaluated as the area under the stressstrain curve up to $\epsilon=1 \%$, for $\mathrm{C} 1$ and ARG specimens in all test groups. It is seen that polymer coating is by far the most efficient in dissipating vast amounts of energy, especially in combination with carbon fabric. However, in line with the previous results, its performance is characterized by large data dispersion, to the extent that, for ARG fabric, confidence bands for polymer and silica coated specimens partially overlap and there is little statistical difference between the two populations.

\section{Conclusions}

In this paper, a novel application of silica nano-coating is considered for interphase bond enhancement of alkali-resistant glass (ARG) and carbon fabric 


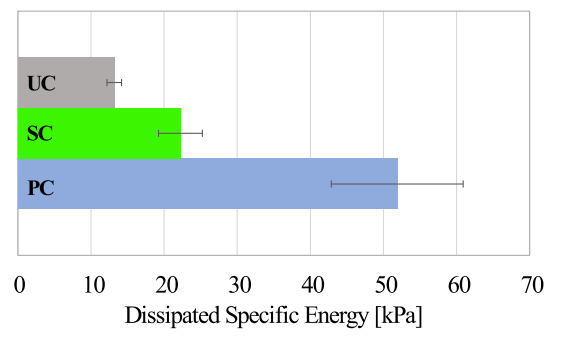

(a)

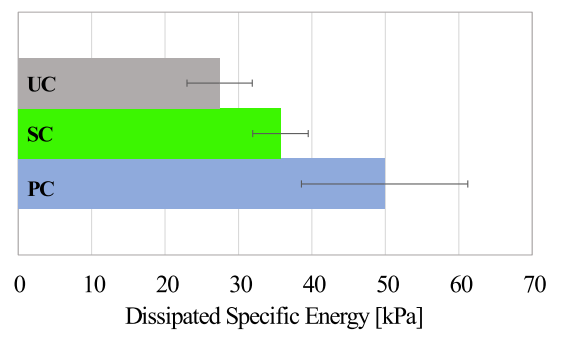

(b)

Figure 30: Dissipated energy and one-standard-deviation bars for uni-axial tensile tests of C1 specimens (a) and ARG specimens (b) in all test groups: uncoated (UC) silica (SC) and polymer coated (PC)

in Textile Reinforced Mortar composites. The effectiveness of the coating is assessed qualitatively through optical and electron microscopy and quantitatively through mechanical tests. Indeed, mechanical performance is determined both through uni-axial traction of rectangular coupons and through three-point bending of laminated clay bricks. Results for the silica coated group are measured against those pertaining to untreated specimens and against the performance of specimens coated through a partially organic impregnation agent (polymer coating). The following conclusions can be drawn:

- silica and polymer coatings determine remarkable gains in terms of mechanical performance for fabric reinforced composite materials;

- in particular, polymer coating brings the best performance in terms of mean ultimate strength, strain, diffuse cracking and energy dissipation for glass fabric specimens in traction and bending;

- the same holds true for carbon fabric, with the noticeable exception of the ultimate strain, which is reduced by the coating, i.e. specimens become more brittle;

- the performance gap with silica coating, however, is greatly mitigated, if not subverted, when design values are considered, for they take into consideration the dispersion of experimental data;

- indeed, polymer coating produces generally wider confidence bands and larger coefficients of variation for design values than silica coating;

- it can be argued, partially on the grounds of microscopy analysis, that this data dispersion is related to the polymeric agent affecting a thick layer of mortar around the fabric. Indeed, the thickness of this layer appears to vary greatly in dependence of many factors among which, in particular, the effectiveness of the impregnation; 
- as a result, silica coating performs as well as, if not better than, polymer coating in terms of design values and this conclusion holds true regardless of whether a three-sigma-rule or characteristic values are adopted to incorporate standard deviation of data into design values.

Results support the important rationale behind material performance optimization, which is targeted at improving design limits rather than mean absolute performance [29]. Finally, the great advantage, in terms of application ease, reproducibility and cost, of industrial pretreatment of the reinforcement fabric cannot be over-emphasized and it should be compared with the difficulty connected to in-situ impregnation of the fabric.

\section{Acknowledgments}

Financial support from the Italian Ministry of Education, University and Research (MIUR) in the framework of the Project PRIN "COAN 5.50.16.01" code 2015JW9NJT - is gratefully acknowledged. The important contribution of Lisa Barilli and Giorgia Martinelli for specimen manufacture is also mentioned.

[1] Mobasher B. Mechanics of fiber and textile reinforced cement composites. CRC press; 2011.

[2] Feo L, Luciano R, Misseri G, Rovero L. Irregular stone masonries: Analysis and strengthening with glass fibre reinforced composites. Compos Part BEng. 2016;92:84-93.

[3] Raoof SM, Koutas LN, Bournas DA. Bond between textile-reinforced mortar (TRM) and concrete substrates: Experimental investigation. Compos Part B-Eng. 2016;98:350-361.

[4] Nadiv R, Peled A, Mechtcherine V, Hempel S, Schroefl C. Micro-and nanoparticle mineral coating for enhanced properties of carbon multifilament yarn cement-based composites. Compos Part B-Eng. 2017;111:179189.

[5] D'Antino T, Papanicolaou C. Mechanical characterization of textile reinforced inorganic-matrix composites. Compos Part B-Eng. 2017;127:78-91.

[6] Nobili A, Falope FO. Impregnated Carbon Fabric-Reinforced Cementitious Matrix Composite for Rehabilitation of the Finale Emilia Hospital Roofs: Case Study. J Compos Constr. 2017;:05017001.

[7] ICC-Evaluation Service . Acceptance criteria for masonry and concrete strengthening using fiber-reinforced cementitious matrix (FRCM) composite systems. AC434; 2013. Whittier, CA.

[8] Kim JK, Mai YW. Engineered interfaces in fiber reinforced composites. Elsevier; 1998. 
[9] $\mathrm{Fu} \mathrm{X}, \mathrm{Lu} \mathrm{W}$, Chung DDL. Improving the bond strength between carbon fiber and cement by fiber surface treatment and polymer addition to cement mix. Cement Concrete Res. 1996;26(7):1007-1012.

[10] Li VC, Stang H. Interface property characterization and strengthening mechanisms in fiber reinforced cement based composites. Adv Cem Based Mater. 1997;6(1):1-20.

[11] Xu Y, Chung DDL. Carbon fiber reinforced cement improved by using silane-treated carbon fibers. Cement Concrete Res. 1999;29(5):773-776.

[12] Li VC, Wu HC, Chan YW. Effect of Plasma Treatment of Polyethylene Fibers on Interface and ementitious Composite Properties. J Am Ceram Soc. 1996;79(3):700-704.

[13] Butler M, Mechtcherine V, Hempel S. Durability of textile reinforced concrete made with AR glass fibre: effect of the matrix composition. Mater Struct. 2010;43(10):1351-1368.

[14] Majumdar AJ. The role of the interface in glass fibre reinforced cement. Cement Concrete Res. 1974;4(2):247-268.

[15] Borri A, Castori G, Corradi M, Speranzini E. Durability Analysis for FRP and SRG Composites in Civil Applications.. Key Eng Mater. 2014;624:421428.

[16] Nobili A. Durability assessment of impregnated Glass Fabric Reinforced Cementitious Matrix (GFRCM) composites in the alkaline and saline environments. Constr Build Mater. 2016;105:465-471.

[17] Micelli F, Aiello MA. Residual tensile strength of dry and impregnated reinforcement fibres after exposure to alkaline environments. Compos Part B-Eng. 2017;. available online.

[18] Nobili A, Signorini C. On the effect of curing time and environmental exposure on impregnated Carbon Fabric Reinforced Cementitious Matrix (CFRCM) composite with design considerations. Compos Part B-Eng. 2017;112:300-313.

[19] Gao SL, Mäder E, Plonka R. Nanostructured coatings of glass fibers: Improvement of alkali resistance and mechanical properties. Acta Mater. 2007;55(3):1043-1052.

[20] Donnini J, Corinaldesi V, Nanni A. Mechanical properties of FRCM using carbon fabrics with different coating treatments. Compos Part B-Eng. 2016;88:220-228.

[21] Scheffler C, Gao SL, Plonka R, et al. Interphase modification of alkaliresistant glass fibres and carbon fibres for textile reinforced concrete I: Fibre properties and durability. Compos Sci Technol. 2009;69(3):531-538. 
[22] Di Maida P, Radi E, Sciancalepore C, Bondioli F. Pullout behavior of polypropylene macro-synthetic fibers treated with nano-silica. Constr Build Mater. 2015;82:39-44.

[23] Lanzoni L, Nobili A, Tarantino AM. Performance evaluation of a polypropylene-based draw-wired fibre for concrete structures. Constr Build Mater. 2012;28(1):798-806.

[24] Nikkanen JP, Huttunen-Saarivirta E, Salminen T, et al. Enhanced photoactive and photoelectrochemical properties of $\mathrm{TiO}_{2}$, sol-gel coated steel by the application of $\mathrm{SiO}_{2}$ intermediate layer. Appl Catal, B. 2015;174:533-543.

[25] ASTM C 947-03 . Standard Test Method for Flexural Properties of ThinSection Glass-Fiber-Reinforced Concrete (Using Simple Beam With ThirdPoint Loading). The American Society for Testing and Materials, West Conshohocken, PA; 2003.

[26] RILEM Technical Committee 232-TDT . Test methods and design of textile reinforced concrete. Mater Struct. 2016;49(12):4923-4927.

[27] Hartig J, Jesse F, Schicktanz K, Häußler-Combe U. Influence of experimental setups on the apparent uniaxial tensile load-bearing capacity of textile reinforced concrete specimens. Mater Struct. 2012;45(3):433-446.

[28] Mobasher B, Peled A, Pahilajani J. Distributed cracking and stiffness degradation in fabric-cement composites. Mater Struct. 2006;39(3):317331.

[29] Gürdal Z, Haftka RT, Hajela P. Design and optimization of laminated composite materials. John Wiley \& Sons; 1999. 